\title{
RELIABILITAS PENDAPAT AHLI PADA FOTOGRAFI FORENSIK DALAM MEMPERKIRAKAN USIA MEMAR
}

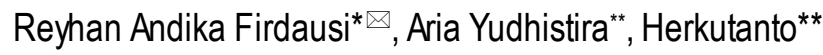

\begin{abstract}
Abstrak
Kemampuan menilai, mendokumentasikan, dan menginterpretasikan luka dengan tepat merupakan bagian penting dari tugas dokter forensik. Salah satu bentuk dokumentasi dalam pemeriksaan kasus forensik klinik adalah foto. Foto luka yang memenuhi kaidah fotografi forensik akan mempermudah dokter untuk melakukan repetitf analisa pada luka dan memberikan keyakinan yang tinggi dalam menuangkan pendapat ahlinya, juga bagi praktisi hukum untuk kepentingan peradilan. Memar merupakan jenis luka yang mempunyai karakteristik unik. Perubahan warna terjadi pada proses penyembuhan memar, sehingga proses dokumentasi luka lebih sulit Saat ini kebanyakan dokter belum mengetahui alat dan teknik fotografi yang baik untuk kepentingan peradilan. Maka, pada penelitan ini dicoba beberapa alat dan teknik fotografi untuk mendokumentasikan luka. Penelitan ini adalah penelitan deskriptif observasional yang betujuan untuk melihat tingkat kesesuaian (reliabilitas) antar pendapat ahli (expert opinion) dalam memperkirakan usia memar dari foto luka. Memar difoto dengan 3 alat fotografi yang berbeda (kamera DSLR, mirrorless, dan handphone). Pengambilan foto dilakukan sebanyak 7 kali untuk masing-masing alat. Delapan kali waktu pengambilan tersebut disesuaikan dengan proses penyembuhan memar. Hasil interpretasi ahli dari foto luka yang dihasilkan kamera DSLR dengan mode manual memiliki tingkat kesesuaian yang lebih tinggi daripada kamera lainnya. Penulis menyimpulkan bahwa dalam melakukan dokumentasi luka sebaiknya menggunakan kamera DSLR dan memakai mode manual. Foto luka yang memenuhi kaidah fotografi forensik dapat membantu dokter dalam menuangkan pendapat ahlinya menjadi lebih baik untuk proses peradilan.
\end{abstract}

Kata kunci: fotografi forensik, usia memar, pendapat ahli.

\section{EXPERT OPINIONS RELIABILITY ON FORENSIC PHOTOGRAPHY IN ASSESSING AGE OF BRUISE}

\begin{abstract}
The wound assessment involves a range of knowledge and skills including ability to interpret the information gained are certainly the most important aspect of a forensic pathologist. A forensic pathologists works on forensic document examination consists of digital photography. Good photography principles will enlighten the doctors to do an analytic repetitive of the wound and a high certainty in order to give their legal opinion. Bruising is one of the most unique wound. The different colours in the healing process that give a difficulty in the documentation process. Most doctors have yet not known the technique of photography in the interest of judiciary and justice,. Therefore, this study used different tools and techniques for wound documentation.The aim of this observasional descriptive research was to evaluate expert opinions on their capability to assess the age of a bruise from a picture and its reliability. Bruise was captured with three different photography devices (DSLR camera, mirrorless, and handphone). Documentation was taken 7 times for each device, which is being adjusted with the healing process of the bruise. The interpretation of wound image by forensic experts was taken with DSLR camera on manual mode has the highest reliabilty rather than the others. It can be concluded that documentation of a wound is better using a DSLR camera and using manual mode. The photographic of wounds that meet the rules of forensic photography will help the doctor to decline a medico-legal assessment.

Keywords: age of bruise, expert opinion, forensic photography.

* Departemen IImu Kedokteran Forensik dan Medikolegal, FK UB

** Departemen IImu Kedokteran Forensik dan Medikolegal, FK UI

ఐE-mail: reyhanmbiz@gmail.com
\end{abstract}




\section{Pendahuluan}

Kemampuan untuk menilai,
mendokumentasikan,
menginterpretasikan luka dengan tepat merupakan bagian penting dari pekerjaan dokter forensik. Tujuan pemeriksaan dan dokumentasi adalah untuk membantu menentukan apa penyebab dan bagaimana mekanisme dari perlukaan tersebut, yang mungkin sering menjadi masalah di pengadilan. Dokter forensik dalam menginterpretasikan luka serta mendokumentasikannya harus dapat membuat deskripsinya secara tertulis, membuat pemetaan grafik tubuh dan memfoto luka. Hal ini sangat penting agar semua orang dapat memahami gambaran luka atau cedera, terutama bagi praktisi hukum. ${ }^{1}$

Di Indonesia, dokter umum merupakan dokter terdepan yang sering berhadapan dengan kasus forensik klinik terutama di Instalasi Gawat Darurat (IGD). Dalam beberapa kasus, pemeriksaan dan penilaian awal mungkin dilakukan untuk tujuan terapeutik murni, dan signifikansi luka baru terlihat setelah beberapa minggu atau bulan kemudian. Tidakjarang pula mereka diminta untuk membuat visum et repertum. Dalam pembuatan visum et repertum tersebut, dokter umum sebagai pemeriksa sering berkonsultasi dengan dokter forensikmelalui sistem konsultasi yang berlaku di Rumah Sakit tersebut. Berikutnya, dokter forensik akan melakukan repetitifanalisa dari catatan rekam medis dan foto yang dibuat oleh dokter pemeriksa yaitu dokter umum. Pemeriksaan dan dokumentasi luka yang tidak baik tentunya akan menyulitkan dokter forensik dan dapat mengganggu proses hukum. ${ }^{1,2}$

Memar merupakan salah satu bentuk luka yang sering ditemukan pada kasus forensik. Dari data Departemen Forensik dan Medikolegal Rumah Sakit Cipto
Mangunkusumo (RSCM) pada tahun 2015, memar menempati jumlah terbanyak kedua setelah luka lecet yaitu sebesar 30 persen dari total semua jenis luka. ${ }^{3}$ Berdasarkan data di RSUP M. Djamil Padang selama 1 tahun antara 2010-2011, memar menempati urutan terbanyak kedua yaitu sebesar 34,8 persen. ${ }^{4}$ Sementara pada kasus kekerasan dalam rumah tangga (KDRT), jenis luka yang paling banyak ditemukan adalah memar yaitu sebesar 79,3 persen. ${ }^{5}$

Setiap luka yang ada pada korban hidup akan mengalami proses penyembuhan. Luka memar merupakan jenis luka yang mempunyai karakteristik unik. Dalam proses penyembuhannya, memar akan mengalami perubahan warna. ${ }^{6}$ Perubahan warna tersebut mungkin akan membuat proses dokumentasi luka lebih sulit. Sehingga membutuhkan kaidah fotografi forensik untuk mendapatkan hasil foto yang baik untuk kepentingan medikolegal.

Pemilihan alat dan teknik fotografi tentunya akan mempengaruhi foto yang dihasilkan. Dalam kedokteran forensik, pilihan alat yang mampu berbicara banyak antara lain kamera dengan format film 35 $\mathrm{mm}$, lensa $28-80 \mathrm{~mm}$, dan pemakaian eksternal flash.7 Selain itu, alat lainnya seperti identification marker berskala juga sangat penting kegunaanya. ${ }^{8}$ Sedangkan teknik fotografi yang dipakai untuk mendokumentasikan sebuah luka adalah tergantung dari kebutuhan pemeriksa (dokter). Kebutuhan tersebut terkait jenis foto apa yang akan dihasilkan, yaitu foto jarak menengah atau foto makro. ${ }^{9}$

Saat ini, alat dan teknik fotografi yang digunakan oleh dokter dalam mendokumentasikan luka masih banyak sekali perbedaan dan variasinya. Walaupun kurikulum tentang fotografi forensik sudah termasuk dalam Standar Kompetensi Dokter Indonesia (SKDI). ${ }^{10}$ 
Foto luka dari kasus forensik klinik merupakan hal yang penting, baik bagi dokter pemeriksa maupun dokter lain yang mungkin akan diminta pendapat ahlinya mengenai suatu kasus forensik klinik. Foto luka yang memenuhi kaidah fotografi forensikakan memberikan kemudahan bagi dokter untuk melakukan repetitif analisa pada luka tersebut dan tentunya akan memberikan keyakinan yang tinggi bagi dokter dalam menuangkan pendapatnya. ${ }^{2}$ Saat ini, kebanyakan dokter belum mengetahui alat dan teknik fotografi yang baik untuk kepentingan medikolegal atau proses penegakan hukum. Untuk itu, dalam penelitian ini, telah dicoba beberapa alatdan teknik fotografi untuk mendokumentasikan luka. Foto-foto tersebut akan diinterpretasi oleh beberapa ahli (dokter spesialis forensik), yaitu melalui deskripsi jenis luka dan usia luka. Hasil interpretasi antar ahli (expert) melalui foto tersebut akan dinilai tingkat kesesuaiannya.

\section{Bahan dan Metode}

Penelitian deskriptif observasional ini bertujuan melihat perbedaan pendapat ahli (expert opinion) dari dokter spesialis forensik dalam memperkirakan usia memar. Dokter spesialis forensik telah melakukan interpretasi memar dari foto yang telah diambil oleh penulis dengan alat dan teknik fotografi yang berbeda-beda. Memar tersebut akan difoto dengan 3 alat fotografi yang berbeda. Pengambilan foto dilakukan sebanyak 7 kali untuk masing-masing alat. Tujuh kali waktu pengambilan tersebut disesuaikan dengan proses penyembuhan memar.

\section{Alat-alat Penelitian}

Alat-alat yang digunakan antara lain: kamera DSLR (Digital Single Lens Reflex) merek Nikon seri D3200 yang dipadukan dengan lensa Nikon 18-55 mm, kamera mirrorless merek Sony a 5000 yang dipadukan dengan lensa Sony $16-50 \mathrm{~mm}$, kamera handphone merek Samsung galaxy $\mathrm{J5}$, tripod merk Victory 3080 , LED video light model DS-1000 dengan color temperature $5500 \pm 200 \mathrm{~K}$, meja fotografi (table top), penggaris/skala ABFO (American Board of Forensic Odontology), I-pad.

Proses pengambilan gambar adalah sebagai berikut: Luka memar yang terdapat pada lengan bawah sisi depan diletakkan di atas meja fotografi, dengan luka memar menghadap ke atas. Lalu, kamera diletakkan di atas luka memar dengan jarak kurang dari $50 \mathrm{~cm}$ (jarak untuk fotografi makro) dengan bantuan tripod. Lensa menghadap ke luka memar secara tegak lurus $\left(90^{\circ}\right)$. Cahaya tambahan dari LED video light dengan kekuatan 5700 K. Penggaris ABFO hitamputih diposisikan sejajar dengan luka dan tidak menutupi luka. Kemudian gambar diambil. Berikutnya kamera diganti dengan kamera lain yang sudah dipersiapkan dan prosedur diulang secara berurutan. Prosedur di atas secara berurutan diulang untuk memar pada punggung.

\section{Metode Pengambilan Gambar \\ Proses pengambilan gambar} dilakukan pada interval waktu sebagai berikut: Jam ke-1, jam ke-6, hari ke-2, hari ke-4, hari ke-6, hari ke-7, dan hari ke-9. Data foto digital yang telah didapat dimasukkan ke i-pad. Penilaian usia luka memar dilakukan oleh 5 dokter spesialis forensik di Departemen Forensik dan Medikolegal RSCM yang sudah bekerja minimal 5 tahun. Penilaian luka secara acak (random) dan blind yang urutan foto sudah ditentukan oleh peneliti. Lalu perkiraan usia memar dicatat (Tabel 1). Berikutnya dinilai perbandingan jumlah interpretasi yang benar dan yang salah antara hasil interpretasi ahli (expert) dengan usia luka yang sebenarnya. 
Tabel 1. Randomisasi foto memar

\begin{tabular}{|c|c|c|c|c|}
\hline Nomor foto & Kamera & Exp.program (mode) & Exp.bias & Usia memar \\
\hline 1 & DSLR & Manual & 0 & $1 \mathrm{jam}$ \\
\hline 2 & DSLR & Manual & 0 & $6 \mathrm{jam}$ \\
\hline 3 & DSLR & Manual & 0 & 2 hari \\
\hline 4 & DSLR & Manual & 0 & 4 hari \\
\hline 5 & DSLR & Manual & 0 & 6 hari \\
\hline 6 & DSLR & Manual & -1 & 9 hari \\
\hline 7 & DSLR & Manual & 0 & 7 hari \\
\hline 8 & Mirrorless & Manual & 0 & $6 \mathrm{jam}$ \\
\hline 9 & Mirrorless & Manual & 0 & 2 hari \\
\hline 10 & Mirrorless & Manual & 0 & 6 hari \\
\hline 11 & Mirrorless & Manual & 0 & 4 hari \\
\hline 12 & Mirrorless & Manual & 0 & 7 hari \\
\hline 13 & Mirrorless & Manual & 0 & $1 \mathrm{jam}$ \\
\hline 14 & Mirrorless & Manual & -1 & 9 hari \\
\hline 15 & Handphone & Auto & 0 & $1 \mathrm{jam}$ \\
\hline 16 & Handphone & Auto & 0 & $6 \mathrm{jam}$ \\
\hline 17 & Handphone & Auto & 0 & 2 hari \\
\hline 18 & Handphone & Auto & 0 & 7 hari \\
\hline 19 & Handphone & Auto & 0 & 6 hari \\
\hline 20 & Handphone & Auto & 0 & 4 hari \\
\hline 21 & Handphone & Auto & -1 & 9 hari \\
\hline
\end{tabular}

\section{Hasil}

Pada Gambar 1 berikut ditampilkan diambil menggunakan tiga jenis kamera hasil foto luka memar pada punggung yang yang berbeda.

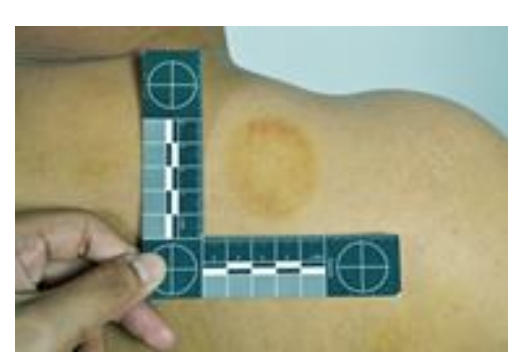

A

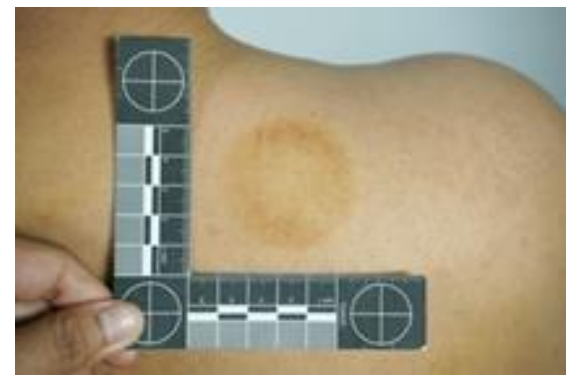

B

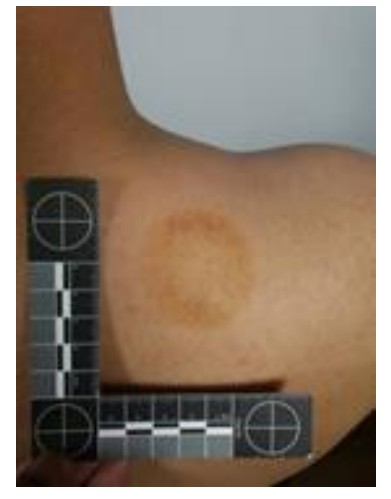

C

Gambar 1. Ambilan foto luka memar yang berusia 6 hari.

Keterangan : A. Diambil dengan kamera DSLR; B. Diambil dengan kamera mirrorless; C. Diambil dengan kamera handphone. 
Dari 21 foto yang sudah diinterpretasi perkiraan usia memarnya oleh 5 expert diketahui bahwa foto yang diambil dengan kamera DSLR lebih banyak kesesuaiannya antara interpretasi expert dengan usia memar yang sebenarnya, dibandingkan dengan foto yang diambil dengan kamera mirrorless dan handphone. Kemudian dari 6 foto memar yang perkiraan usia memarnya antara 7-14 hari, dimana 3 foto diambil dengan exposure bias "0" yang artinya correct exposure dan 3 foto lainnya diambil dengan exposure bias "- 1 " yang artinya underexposure didapatkan hasil bahwa foto memar yang under exposure lebih tinggi tingkat kesesuaiannya dibandingkan dengan foto memar yang correct exposure.

Tabel 2. Jumlah benar dan salah dari perbandingan antara interpretasi usia memar dari ahli (expert) dengan usia memar yang sebenarnya

\begin{tabular}{|c|c|c|c|c|c|c|c|c|c|c|c|}
\hline \multirow[t]{2}{*}{ Expert } & \multicolumn{11}{|c|}{ Foto } \\
\hline & 1 & 2 & 3 & 4 & 5 & 6 & 7 & 8 & 9 & 10 & 11 \\
\hline I & + & + & + & + & - & - & + & - & - & + & + \\
\hline II & + & - & - & - & - & + & + & - & - & - & + \\
\hline III & + & + & + & + & - & + & + & + & + & + & - \\
\hline IV & + & + & + & + & - & + & + & + & - & - & - \\
\hline V & + & + & - & + & - & + & + & + & + & - & + \\
\hline \multirow[t]{2}{*}{ Expert } & \multicolumn{11}{|c|}{ Foto } \\
\hline & 12 & 13 & 14 & 15 & 16 & 17 & 18 & 19 & 20 & 21 & \\
\hline I & + & + & - & + & - & - & + & + & + & - & \\
\hline II & + & - & - & $\mathrm{x}$ & $\mathrm{x}$ & $\mathrm{x}$ & - & - & + & - & \\
\hline III & - & + & - & + & + & + & - & - & - & - & \\
\hline IV & + & + & + & + & - & - & - & - & - & - & \\
\hline $\mathrm{V}$ & + & + & - & + & + & - & + & + & - & - & \\
\hline \multicolumn{12}{|c|}{ Keterangan : " $+\Rightarrow$ benar, $\quad "$ " $\rightarrow$ salah, $\quad " x " \rightarrow$ tidak dapat dinilai expert } \\
\hline
\end{tabular}

Tabel 3. Total nilai "benar" atau "salah" pada setiap kamera

\begin{tabular}{|c|c|c|c|}
\hline Nilai & DSLR & Mirrorless & Handphone \\
\hline Benar & 25 & 19 & 13 \\
\hline Salah & 10 & 16 & 22 \\
\hline
\end{tabular}

Tabel 4. Total nilai "benar" antara foto dengan exposure bias "-1" dan "0"

\begin{tabular}{|c|c|c|c|c|}
\hline Exp.bias & DSLR & Mirrorless & Handphone & $\begin{array}{c}\text { Jumlah nilai } \\
\text { benar }\end{array}$ \\
\hline 0 & 4 & 1 & 0 & 5 \\
\hline-1 & 5 & 4 & 2 & 11 \\
\hline
\end{tabular}

Keterangan: Berdasarkan 15 foto dengan exposure bias "-1" dan 15 foto dengan exposure bias "0" 


\section{Pembahasan}

Pada foto memar yang diambil menggunakan kamera DSLR dengan exposure programe (mode) manual, tingkat kesesuaian antar expert opinions-nya lebih tinggi dibandingkan foto memar yang diambil dengan kamera mirrorless dan handphone. Hal ini menunjukkan bahwa kamera DSLR lebih mumpuni dalam penggunaanya sebagai alat fotografi forensik. Kamera DSLR dapat memberikan keleluasaan bagi penggunanya untuk mengatur segitiga eksposur sesuai dengan kondisi cahaya dan objek yang akan difoto, sehingga hasil foto seimbang dalam hal pencahayaan dan warna serta memiliki ketajaman yang baik. ${ }^{2}$

Pada dasarnya kamera mirrorless memiliki fitur pengaturan yang hampir sama seperti kamera DSLR, bahkan kamera handphone yang canggih saat ini juga ada yang hampir menyamai fitur kamera DSLR. Perbedaan antara kamera DSLR, mirrorless dan handphone terletak pada proses masuknya cahaya atau refraksi cahaya. Kamera DSLR memungkinkan fotografer melihatlangsung objek melalui suatu cermin yang memantulkan cahaya dari luar lalu dipantulkan ke pentaprisma dan akhirnya dapatdilihatdi viewfinder. ${ }^{11,12}$ Hal inilah yang membuat kamera DSLR lebih mumpuni untuk fotografi forensik, karena objek yang terlihat di viewfinder kamera DSLR merupakan bentuk dan warna asli dari objek tanpa ada pengolahan digital sebelumnya, seperti yang disebutkan di literatur yaitu "what you see is what you get". ${ }^{2}$ Sedangkan pada kamera mirrorless, fotografer melihat objek dari LCD yang ada di kamera. Gambar objek sebelum difoto yang ditampilkan di LCD pastinya sudah mengalami pengolahan digital dari kamera, sehingga warna objek yang akan difoto dapat mengalami perubahan. Dalam hal perkiraan usia memar faktor warna dari memar memegang peranan penting, adanya perubahan warna tersebut dapatmembuat expert salah dalam memperkirakan usia memar.

Perbedaan exposure bias juga mempengaruhi hasil interpretasi ahli (expert). Memar yang berusia 7-14 hari secara teori akan berwarna kuning kecoklatan dan warna tersebut sudah mulai memudar bahkan samar dengan warna kulit.6,12 Pada umumnya warna kulit orang Indonesia adalah kuning langsat dan sawo matang (coklat). Foto memar dengan usia memar 7-14 hari yang diambil dengan exposure bias "0" akan membuat ahli (expert) lebih banyak salah dalam menginterpretasikan usia memar karena warna memudar dan gradasi warna lebih samar. Kesalahan interpretasi ini ternyata dapat dikurangi dengan menempatkan eksposure menjadi under. Dengan eksposur under, warna memar akan tampaklebih "tua" sehingga memar akan lebih terlihat dan pada akhirnya dapat memudahkan ahli (expert) dalam melakukan interpretasi usia memar.

Pemakaian mode manual ternyata sangat signifikan fungsinya dalam fotografi forensik. Pengaturan masuknya cahaya melalui pengaturan segitiga eksposur membuat pencahayaan optimal. Pencahayaan yang baik merupakan salah satu aspek yang harus dipenuhi dalam fotografi forensik. ${ }^{2}$ Dengan pencahayaan yang tidak baik dapat membuat dokter forensik salah dalam interpretasi suatu luka. Kesalahan dalam intepretasi luka ini dapat membuat dokter forensik memberikan keterangan ahli yang salah dan mengakibatkan suatu putusan hakim yang tidak tepat.

\section{Kesimpulan}

- Dalam ranah kedokteran forensik, proses dokumentasi luka sebaiknya menggunakan kamera DSLR dan 
- memakai mode manual. Foto luka harus memenuhi kaidah fotografi forensik, yaitu hasil foto harus optimal dalam pencahayaan, memiliki ketajaman obyek foto yang baik, dan tidak ada distorsi warna. Selain itu, foto luka juga harus terukur (berskala) dan berlabel (beridentitas).

- Apabila foto luka memenuhi kaidah fotografi forensik, maka foto tersebut dapat diinterpretasi dengan baik oleh dokter pemeriksa maupun dokter lain yang dimintai pendapat ahlinya.

- Hasil penelitian ini menunjukkan bahwa tingkat reliabilitas antar ahli (expert) pada fotografi forensik sudah terlihat perbedaanya. Masih adanya salah interpretasi foto membuat pemanfaatan foto sebagai sarana untuk repetitif analisa masih perlu penelitian lebih lanjut. Penambahan sampel diperlukan untuk mendapatkan hasil yang signifikan dan akurat.

- Pentingnya warna dalam interpretasi memar memberikan konsekuensi pada dokter forensik untuk menghasilkan foto luka yang tidak mengalami distorsi warna. Pemakaian color chart dapat dijadikan solusi dalam fotografi forensik.

\section{Daftar Pustaka}

1. Stark M. Clinical Forensic Medicine: A Physician's Guide. Second Edition. New Jersey: Humana Press. 2005.

2. Idries AM, Tiptomartono AL. Penerapan IImu Kedokteran Forensik Dalam Proses Penyidikan. Jakarta: Sagung Seto. 2011.

3. Nafisah, ZF. Hubungan Antara Temuan Luka Akibat Kekerasan Tumpul di Dada dengan Kerusakan Organ di Dalamnya.
Skripsi. Jakarta: Universitas Indonesia. 2015.

4. Riandini IL, Susanti R, Yanis A Gambaran Luka Korban Kecelakaan Lalu Lintas yang Dilakukan Pemeriksaan di RSUP Dr M Djamil Padang. Jurnal Kesehatan Andalas. 2015;

http://jurnal.fk.unand.ac.id/index.php/jka/ article/viewFile/283/270 Diakses 4 Mei 2017.

5. Affandi D, Rosa WY, Suyanto, Khodijah, Widyaningsih C. Karakteristik Kasus Kekerasan dalam Rumah Tangga. Journal Indonesia Medical Association. 2012; 62(11).

6. Budiyanto A. IImu Kedokteran Forensik. Jakarta: Bagian Kedokteran Forensik Fakultas Kedokteran Universitas Indonesia. 1997.

7. Reis G. Photoshop CS3 for Forensic Professionals. Indianapolis: Wiley Publishing. 2007.

8. Robinson E. Crime Scene Photography. Washington: Academic Press. 2010.

9. Duncan CD. Advanced Crime Scene Photography. Boca Raton: CRC Press. 2009.

10. Konsil Kedokteran Indonesia. Standar Kompetensi Dokter Indonesia. Jakarta: Konsil Kedokteran Indonesia. 2012.

11. Fauzan S. Modul Sejarah Perkembangan Fotografi dan Anatomi Kamera. $\quad$ (Online). 2015. https://performaupi.files.wordpress.com/ 2013/12/sejarah-perkembanganfotografi-dan-anatomi kamera.pdf. Diakses 5 Agustus 2015.

12. Wells D. Injury Interpretation. The Department of Forensic Medicine, Monash University. Chrchill Victoria: Distance Education Centre Monash University. 1999. 